\title{
Genetic Modification of Primate Amniotic Fluid-Derived Stem Cells Produces Pancreatic Progenitor Cells in vitro
}

\author{
Yu Zhou ${ }^{b}$ David L. Mack ${ }^{a} \quad$ J. Koudy Williams ${ }^{a}$ Sayed-Hadi Mirmalek-Sani ${ }^{a}$ \\ Emily Moorefield $^{\mathrm{a}}$ So-Young Chun ${ }^{\mathrm{c}}$ Jun Wang ${ }^{\mathrm{a}}$ Diego Lorenzetti ${ }^{\mathrm{b}}$ \\ Mark Furth $^{\mathrm{a}}$ Anthony Atala $^{\mathrm{a}}$ Shay Soker ${ }^{\mathrm{a}}$ \\ ${ }^{a}$ Wake Forest Institute for Regenerative Medicine, and ${ }^{b}$ Plureon Corporation, Winston Salem, N.C., USA; \\ 'Joint Institute for Regenerative Medicine, Kyungpook National University Hospital, Daegu, South Korea
}

\section{Key Words}

Amniotic fluid stem cells · Differentiation - Diabetes •

Pancreas $\cdot \beta$-Cells $\cdot$ Cell therapy $\cdot$ Nonhuman primates

\begin{abstract}
Insulin therapy for type 1 diabetes does not prevent serious long-term complications including vascular disease, neuropathy, retinopathy and renal failure. Stem cells, including amniotic fluid-derived stem (AFS) cells - highly expansive, multipotent and nontumorigenic cells - could serve as an appropriate stem cell source for $\beta$-cell differentiation. In the current study we tested whether nonhuman primate (nhp) AFS cells ectopically expressing key pancreatic transcription factors were capable of differentiating into a $\beta$-cell-like cell phenotype in vitro. nhpAFS cells were obtained from Cynomolgus monkey amniotic fluid by immunomagnetic selection for a CD117 (c-kit)-positive population. RT-PCR for endodermal and pancreatic lineage-specific markers was performed on AFS cells after adenovirally transduced expression of PDX1, NGN3 and MAFA. Expression of MAFA was sufficient to induce insulin mRNA expression in nhpAFS cell lines, whereas a combination of MAFA, PDX1 and NGN3 further induced insulin expression, and also induced the expression of other important endocrine cell genes such as glucagon, NEUROD1, NKX2.2, ISL1 and PCSK2. Higher induction of
\end{abstract}

these and other important pancreatic genes was achieved by growing the triply infected AFS cells in media supplemented with a combination of B27, betacellulin and nicotinamide, as well as culturing the cells on extracellular matrixcoated plates. The expression of pancreatic genes such as NEUROD1, glucagon and insulin progressively decreased with the decline of adenovirally expressed PDX1, NGN3 and MAFA. Together, these experiments suggest that forced expression of pancreatic transcription factors in primate AFS cells induces them towards the pancreatic lineage.

Copyright $\odot 2013$ S. Karger AG, Basel

\begin{tabular}{ll}
\hline Abbreviations used in this paper \\
\hline AFS cells & $\begin{array}{l}\text { amniotic fluid-derived stem cells } \\
\text { cycle threshold }\end{array}$ \\
Ct & extracellular matrix \\
ECM & embryonic stem cells \\
ES cells & green fluorescent protein \\
GFP & minimum essential medium \\
MEM & multiplicity of infection \\
MOI & nicotinamide \\
NAD & nonhuman primate \\
nhp & quantitative reverse transcription-polymerase chain \\
qRT-PCR & reaction \\
T1D & type 1 diabetes
\end{tabular}

\section{KARGER}

Fax +4161306 1234

E-Mail karger@karger.ch

www.karger.com
(C) 2013 S. Karger AG, Basel

$1422-6405 / 13 / 1974-0269 \$ 38.00 / 0$

Accessible online at:

www.karger.com/cto
Prof. Shay Soker

Wake Forest Institute for Regenerative Medicine

Wake Forest University School of Medicine

Medical Center Boulevard, Winston Salem, NC 27157 (USA)

E-Mail ssoker@wakehealth.edu 


\section{Introduction}

Diabetes mellitus is a vast and growing medical problem in the USA and world-wide, with a huge impact on healthcare costs [Adeghate et al., 2006; Tao and Taylor, 2010]. The disease affects over 18 million people in the USA. About $10 \%$ of these affected individuals have type 1 diabetes (T1D), resulting from autoimmune destruction of insulin-producing $\beta$-cells in the islets of Langerhans of the pancreas. The majority of patients have type 2 diabetes, which is manifested initially by insulin resistance, but often culminates in the loss of $\beta$-cell mass and a need for insulin replacement therapy [Bouwens and Rooman, 2005]. Unfortunately, consistent glucose homeostasis remains difficult to achieve with any current method of exogenous insulin replacement [Gomis and Esmatjes, 2004]. When glucose metabolism is deregulated over the long term, complications affecting the eyes, kidneys, nerves and cardiovascular system are common [Santiago, 1993; Melendez-Ramirez et al., 2010]. Only transplantation of insulin-producing tissue consistently gives the desired outcomes of euglycemia and avoidance of episodes of hypoglycemia [Bigam and Shapiro, 2004; Davis and Alonso, 2004]. Islet cell transplantation has become a viable clinical modality for a selected cohort of patients with T1D. The procedure is safe and achieves improved metabolic control and quality of life [Ricordi and Strom, 2004; Poggioli et al., 2006; Ryan et al., 2006; Mineo et al., 2009]. A major drawback of this procedure is that 2-3 donor organs per recipient are required to obtain the desired islet mass [Ryan et al., 2005], as the islet cells are nonexpandable and a significant proportion lose viability during islet isolation [Hering et al., 2005]. In addition, islets are lost over time after transplantation, causing about $90 \%$ of patients to require at least some readministration of exogenous insulin [Ricordi and Strom, 2004; Leitao et al., 2008; Ichii and Ricordi, 2009]. These shortcomings cause the current supply of donated pancreata to fall far short of the medical demand by patients who would benefit from transplantation. Therefore, a major translational goal of this work is to resolve the supply/demand mismatch by developing a cell-based therapy for diabetes using amniotic fluid-derived stem (AFS) cells. AFS cells can be expanded extensively in culture, can be differentiated in vitro to cell types from all three germ layers and do not form teratomas when implanted into immunocompromised mice [De Coppi et al., 2007]. In addition, their in vivo regenerative capacity was demonstrated in two different animal models of tissue injury. AFS cells had a protective effect on the kidneys of mice with acute tubular necrosis [Perin et al., 2010] and could integrate and differentiate into epithelial lineages of the lung after injury [Carraro et al., 2008]. Thus, the accumulating data to date suggests that AFS cells may represent an intermediate phenotype between embryonic stem (ES) cells and various lineage-restricted adult stem cells. The choice to use nonhuman primate (nhp)AFS cells arose from the desire to develop a clinically applicable cell therapy for T1D using cells from unrelated allogeneic donors. Primates have been well characterized as animal models of both type 2 diabetes [Wagner et al., 2006] and islet/cell transplantation in streptozotocin-induced T1D [Kenyon et al., 1999a, b; Han et al., 2002; Berman et al., 2007].

Despite recent advances, no in vitro approach has yet been documented in which human, nonembryonic stem cells can safely, reproducibly and efficiently be differentiated into glucose-responsive, insulin-producing $\beta$-like cells or islet-like structures at a scale suitable for clinical use [Raikwar and Zavazava, 2009]. In contrast, multiple laboratories have successfully generated pancreatic endocrine cells or more differentiated insulin-producing cells and islet-like clusters from embryonic stem cells in vitro [D’Amour et al., 2006; Jiang et al., 2007a, b; Cai et al., 2009]. The formation of glucose-responsive insulin-producing $\beta$-cells capable of treating hyperglycemia in mice have been produced by recapitulating embryonic pancreatic development in vitro starting from embryonic stem cells [Kroon et al., 2008]. However, in all cases the efficiency of differentiation is low, while residual undifferentiated pluripotent stem cells have high potential to form teratomas, thus precluding their clinical application [Martin, 1981; Thomson et al., 1998]. In fact, one study that used insulin-producing cells generated from ES cells failed due to teratoma formation [Fujikawa et al., 2005]. Transplantation of purified $\beta$-cells has been shown to be as effective as transplantation of intact islets in reversing hyperglycemia suggesting that a higher order islet structure is not essential [King et al., 2007]. Stable transdifferentiation of somatic cells to insulin-producing cells has also been demonstrated starting from liver tissue [Ber et al., 2003; Kojima et al., 2003] or pancreatic exocrine cells [Zhou et al., 2008] by the forced overexpression of the pancreatic specific transcription factors. Gage et al. [2010] subjected amniotic fluid cells to combinatorial high content screening using an adenoviral-mediated expression system to look for genes that could activate insulin promoter expression linked to a fluorescent reporter. A panel of six transcription factors was identified and included genes that had been previously shown to be critical for development of the endocrine pancreas as well as islet cell 
differentiation (Pdx1, NeuroD, Ngn3, Isl-1, Pax6 and MafA). However, the induction of insulin expression was relatively low in vitro and these same transplanted cells were unable to reverse hyperglycemia in a streptozotocininduced mouse model of diabetes [Gage et al., 2010]. This study determined whether nhpAFS cells could be genetically modified to a $\beta$-cell-like phenotype by the transgenic overexpression of pancreatic transcription factors Pdx1, Ngn3 and MafA. Adenovirus and lentivirus were chosen because these viral reagents are easy to produce and have high transduction efficiency. In future work other types of gene transduction systems could be applied for clinical purpose. The coordinated expression of pancreatic lineage markers was tested by quantitative reverse transcription-polymerase chain reaction (qRT-PCR). Alternative growth conditions that promoted the survival and sustained pancreatic differentiation of the reprogrammed AFS cells were also developed.

\section{Materials and Methods}

\section{Cell Culture}

nhp amniotic fluid was obtained from Cynomolgus monkey amniotic fluid, under a research protocol approved by the Wake Forest School of Medicine Institution Care and Use Committee. The AFS cells were isolated by immunomagnetic sorting for the c-kit-positive population using the CD117-antibody MicroBead Kit (Miltenyi Biotec Inc., cat No. 130-091-332). Clonal AFS lines were generated by the limiting dilution method. AFS cells were grown in modified Chang media [De Coppi et al., 2007].

\section{Adenovirus Production}

Adenovirus expressing mouse Pdx1 was a gift from Christopher Newgard and Sarah Ferber at Duke University. Adenovirusexpressing mouse MafA and nuclear green fluorescent protein (GFP) under the control of CMV promoter was obtained from Addgene [Zhou et al., 2008]. Human NGN3 cDNA was subcloned into pShuttle CMV and pAd Track CMV vector to make adenovirus in the AdEasy viral system [Luo et al., 2007]. Adenoviruses were amplified in human embryonic kidney 293 cells. Adenovirus preparations were titered by infecting 293 cells with diluted virus in 6-well plates. After 12-16 h the cells were collected and fixed with $2 \%$ paraformaldehyde and permeabilized with cold $100 \%$ methanol. The cells were stained with mouse anti-E2A antibody (a gift from Dr. David Ornelle) and Cy5-goat anti-mouse (Fab') ${ }^{2}$ antibody (Jackson ImmunoResearch Inc., West Grove, Pa., USA). The percentage of infected cells was determined by flow cytometry and the infectious units per cell were calculated based on the Poisson distribution. Viral-mediated gene expression was confirmed by immunostaining with specific antibodies: Anti-Pdx1 monoclonal antibody (Clone 267712) from R\&D Systems (Minniapolis, Minn., USA), rabbit anti-human NGN3 polyclonal antibody (H-80) from Santa Cruz Biotechnology Inc. (Santa Cruz, Calif., USA) and rabbit anti-mouse MAFA antibody from Abcam (Cambridge, UK).

Pancreatic Differentiation of Primate AFS Cells

\section{Lentivirus Production}

A 3-in-1 lentiviral vector (pLenti-MafA-Ngn3-Pdx1) expressing the human MAFA, NGN3 and PDX1 genes was purchased from Applied Biological Materials (ABM, Richmond, BC, Canada). The MAFA gene was under the control of the mini CMV promoter while NGN3 and PDX1 were under the control of the PGK promoter. Lentivirus was produced in $293 \mathrm{~T}$ cells following the methods of Kutner et al. [2009]. Crude supernatant containing lentiviral particles was concentrated with Lenti-X Concentrator (Clontech Laboratories Inc., Mountain View, Calif., USA).

\section{AFS Cell Infection and Differentiation}

NhpAFS cells were seeded at $60-70 \%$ confluence $24 \mathrm{~h}$ before adenoviral infection. Just prior to viral infection, culture media was aspirated and cells were rinsed twice with $1 \times$ PBS. Adenovirus at the indicated multiplicity of infection (MOI) in serum-free $\alpha$-minimum essential medium (MEM) was added to the cells at minimal volume that ensures cell coverage. Plates were rocked gently every $15 \mathrm{~min}$ for the first hour and incubated for another $2-3 \mathrm{~h}$ at $37^{\circ} \mathrm{C}$ in a $\mathrm{CO}_{2}$ incubator after which the infection media was replaced with normal culture media. Differentiation inducing media contained $\alpha$-MEM supplemented with 2\% B27 (Invitrogen, San Diego, Calif., USA), $10 \mathrm{ng} / \mathrm{ml}$ Betacellulin (Peprotech, Rocky Hill, N.J., USA) and $10 \mathrm{~mm}$ nicotinamide (NAD; Sigma, St. Louis, Mo., USA).

\section{Quantitative Reverse Transcription-Polymerase Chain \\ Reaction}

Total RNA was isolated from virally-infected and uninfected control AFS cells using PerfectPure RNA cultured cell kit (5 Prime Inc., Gaithersburg, Md., USA) and treated with DNase according to the manufacturer's protocol. cDNA was prepared using High Capacity cDNA Reverse Transcription kit (Applied Biosystems, Foster City, Calif., USA). qPCR was performed in $20 \mu \mathrm{l}$ reactions in 96-well plates using cDNA samples from $6.25 \mathrm{ng}$ of total RNA. Taqman probes (Applied Biosystems) specific for primate genes are listed in table 1 . For insulin detection, two primers, NHPINS-F29 (5'-aggtcagcaagcaggtcact- ${ }^{\prime}$ ) and NHPINS-R151 $\left(5^{\prime}\right.$-cacaggtgctggttcacaaa- $\left.3^{\prime}\right)$ were designed based on primate insulin cDNA sequence (Accession No. J00336.1 gi:342121). qPCR was performed with these primers in the presence of Power SYBR Green PCR Master Mix (Applied Biosystems) in an ABI 7300 Real-Time PCR System. For insulin qPCR there was only one peak in the dissociation curve. Insulin PCR product was sequenced to confirm specificity of the primers and to show that it matched the preproinsulin sequence obtained from monkey pancreas extracted cDNA [Wetekam et al., 1982]. The undetectable level of fluorescence was set at a cycle threshold (Ct) of 38 .

For detection of exogenous (adenovirally expressed) PDX1, NGN3 and MAFA, AFS cells were transduced at an MOI of 100 and then cultured in modified Chang media (the same media AFS cells are grown in to maintain them in their undifferentiated state). Total RNA from transduced cells was extracted 3, 6 and 9 days after adenovirus infection. qRT-PCR was used to detect the expression of exogenous transcription factors and endogenous pancreatic lineage marker genes. Mouse PDX1 Taqman probe (Mm00435565-m1; ABI), human NGN3 primers (hNGN3-F28 ACTGTCCAAGTGACCCGTGA, hNGN3-R232 TCAGTGCCAACTCGCTCTTAG) and GFP primers (GFP-F ACGTAAACGGCCACAAGTTC, GFP-R AAGTCGTGCTGCTTCATGTG) were used to detect exogenous gene expression of mouse PDX1, 
Table 1. Marker expression in undifferentiated primate AFS cell clones

\begin{tabular}{|c|c|c|c|c|c|}
\hline CD44 & 22.4 & 23.2 & 23.1 & 26.6 & Rh02829215_m1 \\
\hline CD90 & 27.1 & 27.2 & 28.6 & 30.6 & Rh02860204_m1 \\
\hline CD146 & 28.1 & 26.3 & 26.3 & 29.3 & Rh02861012_m1 \\
\hline EPCAM & 32.7 & 37.4 & 36.6 & 25.4 & Rh02841959_m1 \\
\hline GATA4 & undetectable & undetectable & undetectable & 27.2 & Rh02840876_m1 \\
\hline SOX9 & 31.5 & 34.9 & 29.3 & 28.2 & Rh01001343_m1 \\
\hline PDX1 & undetectable & undetectable & undetectable & 27.6 & Rh02902569_m1 \\
\hline NGN3 & undetectable & undetectable & undetectable & 37.9 & Rh02819089_m1 \\
\hline PAX4 & undetectable & undetectable & undetectable & 31.3 & Rh02913666_m1 \\
\hline NEUROD1 & undetectable & undetectable & undetectable & 26.0 & Rh02913666_m1 \\
\hline GLP1R & undetectable & undetectable & undetectable & 27.4 & Rh02840909_m1 \\
\hline GLUT2 & undetectable & undetectable & undetectable & 28.2 & Rh02828080_m1 \\
\hline PCSK2 & undetectable & undetectable & undetectable & 24.4 & Rh02842756_m1 \\
\hline INS & undetectable & undetectable & undetectable & 15.2 & see Materials and Methods \\
\hline GCG & 36.5 & 37.5 & undetectable & 19.0 & Rh02840882_m1 \\
\hline SST & undetectable & 29.4 & 32.7 & 25.1 & Rh02912807_m1 \\
\hline PPY & 37.9 & 34.0 & undetectable & 27.1 & Rh02929042_m1 \\
\hline ACTB & 17.1 & 17.2 & 17.3 & 22.0 & Rh03043379_gH \\
\hline GAPDH & 17.4 & 19.3 & 18.1 & 22.6 & Rh02621745_g1 \\
\hline 18 srRNA & 14.2 & 13.8 & 13.7 & 13.6 & $433760 \mathrm{~F}$ \\
\hline
\end{tabular}

cDNA samples from about $6.25 \mathrm{ng}$ total RNA were analyzed by qRT-PCR using ABI rhesus monkey Taqman probes or SYBR GREEN PCR (INS) system. Insulin primers were designed based on monkey insulin sequence (J00336.1). Values represent average $\mathrm{Ct}$ of triplicate reactions. The undetectable Ct cutoff was 38 cycles.
Ct value <20: very high expression level; Ct value 20-25: high expression; Ct value 25-30: moderate to high expression; Ct value 30-35: low expression; Ct value 35-38: low to negligible expression; Ct value $\geq 38$ : undetectable level. human NGN3 and mouse MAFA linked to GFP. The MafA/nGFP adenoviral construct has nuclear-expressed GFP linked with the MafA cDNA by an IRES allowing the two genes to be co-transcribed. Therefore, MAFA message was determined qRT-PCR using GFP primers and protein expression was demonstrated by the presence of nuclear GFP fluorescence, which was confirmed by MAFA immunostaining. For detection of exogenous human PDX1, NGN3 and MAFA expression from lentivirus, AFS cells were transduced with different dilutions of concentrated lentivirus. The highest concentration of lentivirus which did not show toxicity to cells in 3 days was used for the experiment. Human Pdx1 Taqman probe (Hs00426216_m1; ABI), human NGN3 primers (the same as before) and human MAFA Taqman probe (Hs001651425_s1; ABI) were used to detect exogenous gene expression from the 3-in-1 lentivirus.

Cell Viability Analysis by MTS Assay

For evaluation of cell survival, PDX1, NGN3 and MAFA adenovirus triply infected cells were cultured in 96-well plates with
$100 \mu \mathrm{l}$ of culture media per well for different amounts of time. The 96-well plate was precoated with or without extracellular matrix (ECM) protein including collagen IV $\left(10 \mu \mathrm{g} / \mathrm{cm}^{2}\right.$, Sigma C-5533), fibronectin (4 $\mu \mathrm{g} / \mathrm{cm}^{2}$, Millipore FC010) and laminin $\left(2 \mu \mathrm{g} / \mathrm{cm}^{2}\right.$, Sigma L6274). Twenty microliters of CellTiter $96^{\circledR}$ AQueous One Solution Reagent (Promega, Madison, Wisc., USA) was added per well at the different time points. The plate was incubated at $37^{\circ} \mathrm{C}$ for $2 \mathrm{~h}$ and the absorbance was read at $490 \mathrm{~nm}$ using SpectraMax M5 spectrophotometer (Molecular Devices, Sunnyvale, Calif., USA).

\section{Results}

\section{Isolation of nhpAFS Cells}

Multiple clonal lines of nhpAFS were isolated from Cynomolgus monkey amniotic fluid according to the 


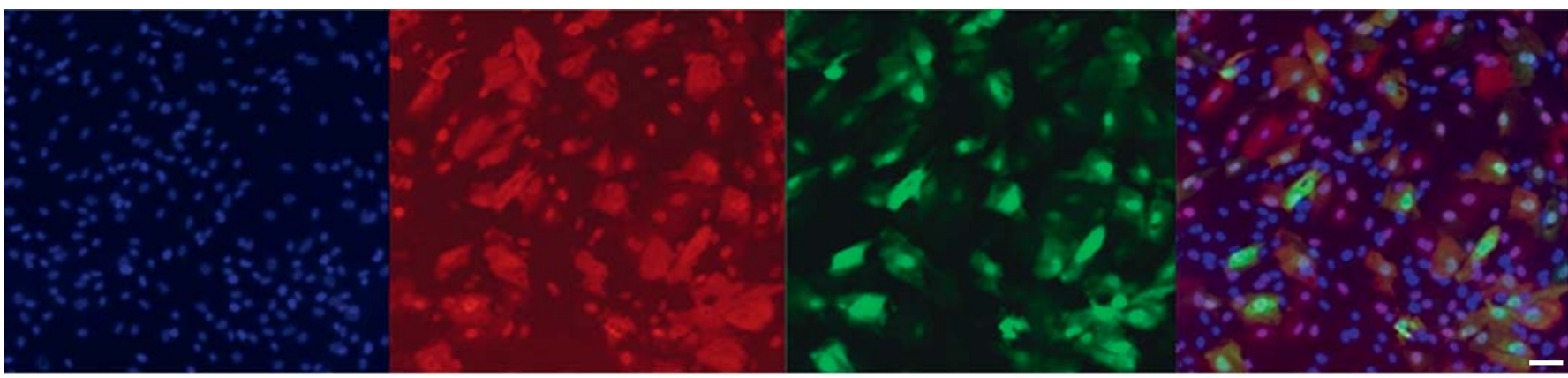

b

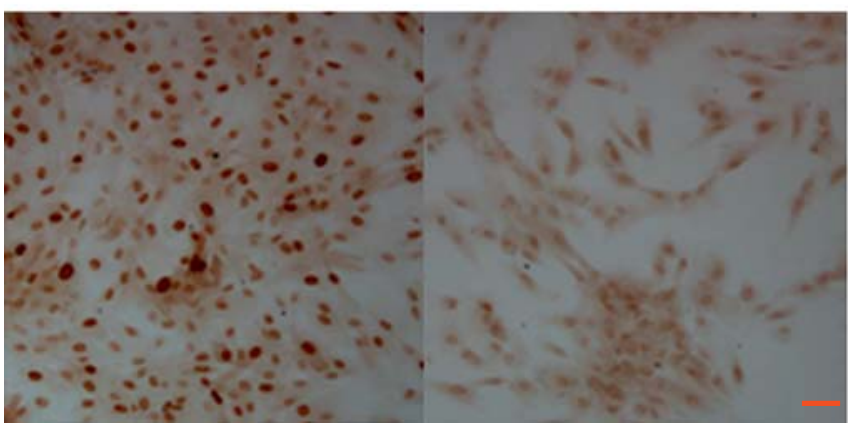

Fig. 1. Ectopic expression of pancreatic genes in nhpAFS cells. Cells were infected at an MOI of 100 each for adenoviral vectors (Ad) expressing PDX1, NGN3/GFP, MAFA/nGFP and their combinations. a, c After $48 \mathrm{~h}$, ectopic gene expression of PDX1 and MAFA was detected by immunofluorescence. NGN3 gene expression was detected by anti-Ngn3 immunostaining (b). Overex- c

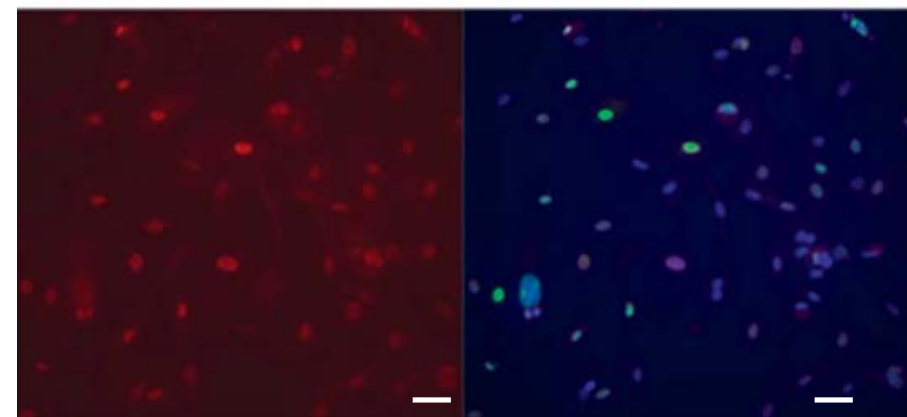

pressed PDX1 protein could be detected in both the cytoplasm and nucleus (a) while NGN3 and MAFA were only detected in the nucleus. Over $50 \%$ of the transduced cells expressed the target transcription factors. Double infection with PDX1 and NGN3/ GFP showed that most NGN3/GFP-positive cells were also Pdx1 positive, as shown by orange staining (a). Scale bar $=50 \mu \mathrm{m}$. same methods employed for human AFS cells [De Coppi et al., 2007]. AFS cells were passaged between 30 and $80 \%$ confluency in order to maintain full differentiation capacity. Cell morphology of different lines was consistent with that of a fibroblast-like morphology resembling a mesenchymal stromal cell population. Given that the principle isolation criteria after c-kit selection is the adherence to tissue culture plastic, this observation is consistent with the mesenchymal origin of these cells. This phenotype was confirmed in all lines generated by the expression of typical mesenchymal stem cell markers, such as CD44 (hyaluronic acid receptor), CD73 (5'ribonucleotide phosphohydrolase), CD90 (Thy-1) and CD146 (MCAM), plus others shown in table 1.

\section{Induction of Pancreatic Gene Expression by}

Overexpression of Pancreatic-Specific Transcription

Factors

To rule out that the nhpAFS cells originated from an endodermal lineage, it was important to first verify that pancreatic-specific gene expression was not present in the undifferentiated cells. Table 1 also shows that PDX1, NGN3, PAX4, NEUROD1, ISL1, GLP1R, GLUT2, PCSK2 and INS (insulin) were undetectable by RT-PCR in all three clones analyzed. However, low-level expression of PAX6 and NKX6.1 could be detected in two of the primate AFS clones (NHP7405 and NHP7880), while one clone (NHP7880) showed barely detectable levels of NKX2.2 and two clones (NHP7231 and NHP7405) showed GCG (glucagon) expression just above the negative cutoff. We subsequently tested the effects of pancreatic-specific transcription factors, introduced via adenoviral-mediated transduction, on nhpAFS cell differentiation to pancreatic lineages. Three key transcription factors, PDX1, NGN3 and MAFA, either singly or in combination, were transiently expressed in AFS cells from the adenoviral CMV promoter and compared to the control GFP-expressing adenovirus. Figure 1 confirms that overexpressed PDX1 protein could be detected in both the cytoplasm and the nucleus (fig. 1a), while NGN3 and 


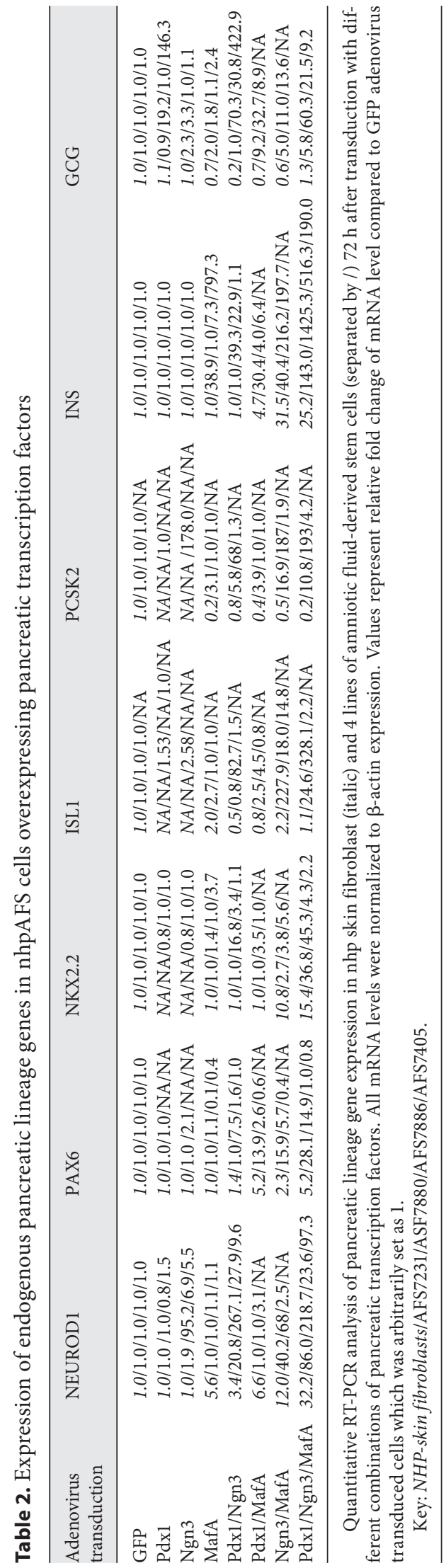

MAFA were only detected in the nucleus. Over $50 \%$ of the transduced cells expressed the target transcription factors. Double infection with PDX1 and NGN3/GFP showed that most of the NGN3-positive cells (GFP) were also PDX1 positive (red; fig. 1a). Three days after viral transduction, the expression of genes, restricted to different stages along the pancreatic differentiation pathway, was assayed by qRT-PCR. The GFP control vector was unable to induce expression of any of the pancreatic marker genes tested. Each transcription factor alone was able to induce very few markers (table 2). NGN3 can induce NeuroD1 in most of the cell lines tested but was unable to induce insulin. MAFA was able to induce insulin in some lines such as NHP7231 and to a much greater extent in NHP7405. PDX1 induced glucagon expression in two cell lines (NHP7880 and NHP7405) which had relatively high expression of endogenous PAX6 and NKX6.1 gene but could not induce glucagon expression in PAX6- and NKX6.1-low cells such as NHP7231 and NHP7886. NGN3 and MAFA were unable to induce GCG expression even in PAX6- and NKX6.1-expressing cells. Two-factor combinations were able to induce the expression of more marker genes and with higher expression levels. For example, PDX1 and NGN3 invariably induced higher expression of NeuroD1 than NGN3 only. Three transcription factor combinations further improved the capability of inducing the expression of pancreatic marker genes in all the primate AFS cell lines tested. Figure 2 shows the relative fold change in expression of selected pancreatic genes in primate AFS cells after the introduction of one, two or three transcription factors. In NHP7880 exogenous NGN3 expression induced high-level NeuroD1 expression and that level was increased by the introduction of PDX1 but not by MAFA.

\section{Continuous, High-Level PDX1, NGN3 and \\ MAFA Expression Is Necessary for Induction and Maintenance of the Pancreatic Gene Expression}

To determine the correlations between the levels of forced expressed pancreatic transcription factors (PDX1, NGN3 and MAFA) and the endogenous expression of pancreatic genes in nhpAFS cells, we measured their expression at 3, 6 and 9 days after transduction with all 3 transcription factors. Ectopic expression of the three transcription factors from the adenoviral CMV promoters is transient and decreases over time as the episomal virus is diluted during cell division. All three exogenous transcription factors reach their maximum expression on day 3 after transduction and then steadily decrease over time (fig. 3a). Figure $3 \mathrm{~b}$ shows that NeuroD1, insulin and 


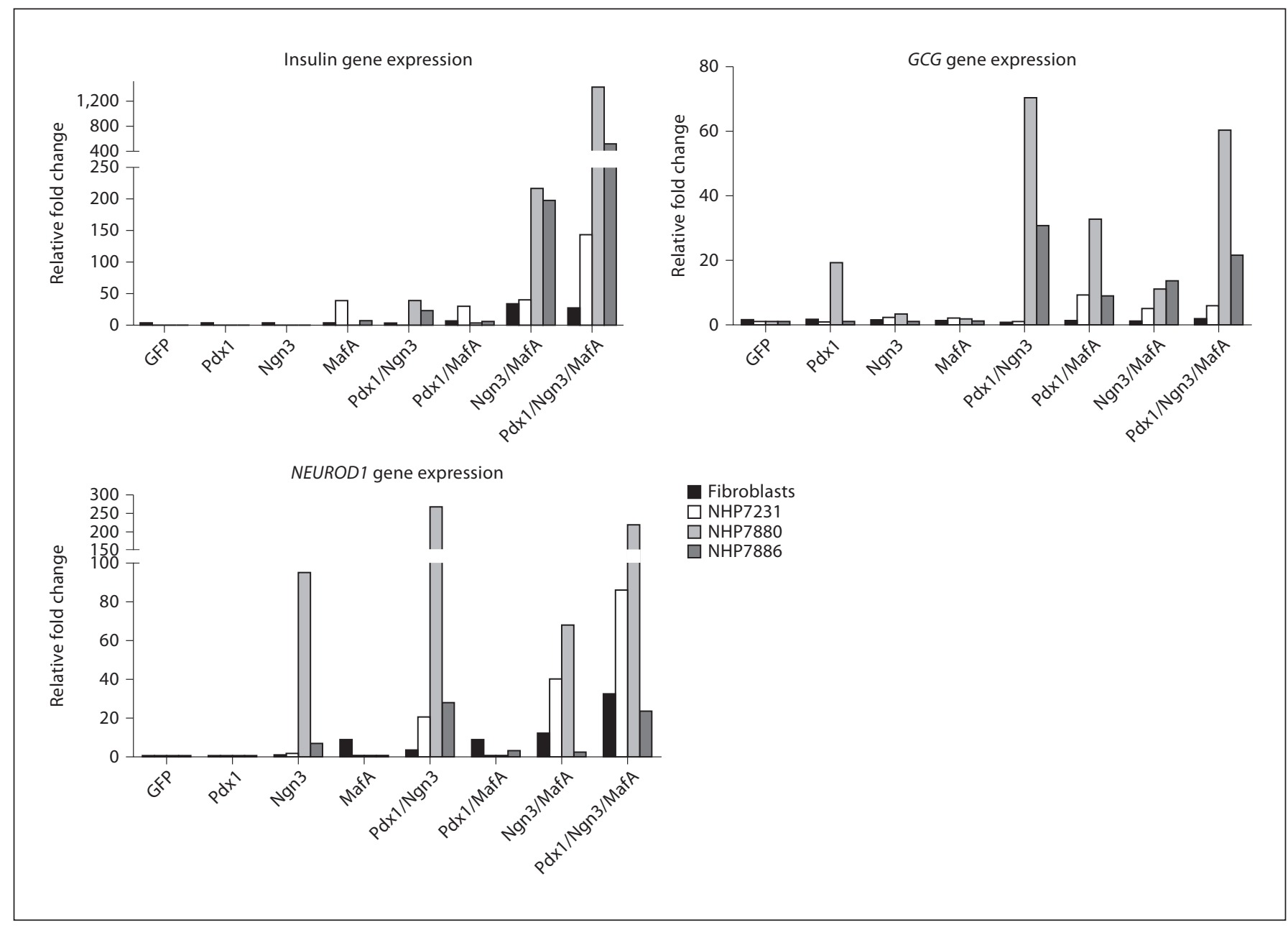

Fig. 2. Expression of endogenous insulin, glucagon and NeuroD1 in nhpAFS cells overexpressing pancreatic transcription factors. Expression data from table 1 is presented as single graphs for insulin, glucagon and NeuroD1. Experimental details are the same as in table 2.

glucagon expression decreases over the 9-day time course, paralleling expression of the adenoviral-mediated expressed PDX1, NGN3 and MAFA. Although expression of exogenous transcription factors was still relatively high at day 9, the expression of endogenous pancreatic marker genes was barely detectable suggesting that continued high-level transcription factor expression is necessary to maintain the long-term pancreatic lineage phenotype. These results suggest that maintenance of the pancreatic phenotype is dependent on continued exogenous transcription factor expression.

If stable and elevated expression of PDX1, NGN3 and MAFA in nhpAFS cells is required to maintain expression of pancreatic lineage genes, a 3-in-1 lentiviral expres- sion system may prove to be a superior approach. Lentiviral-mediated expression originates from stable integration of the transgenic construct into the host cell genome. Long-term transcription factor expression was achieved using the lentiviral system (data not shown); however, it expressed approximately 10 -fold less PDX1, 250-fold less NGN3 and 200-fold less MafA (fig. 3c). The lentiviralinfected cells did not show elevated expression of pancreatic genes after 6 days in culture. This observation is consistent with our previous finding (fig. 3a, b) that highlevel transcription factor expression was necessary for the sustained expression of endogenous pancreatic marker genes. 


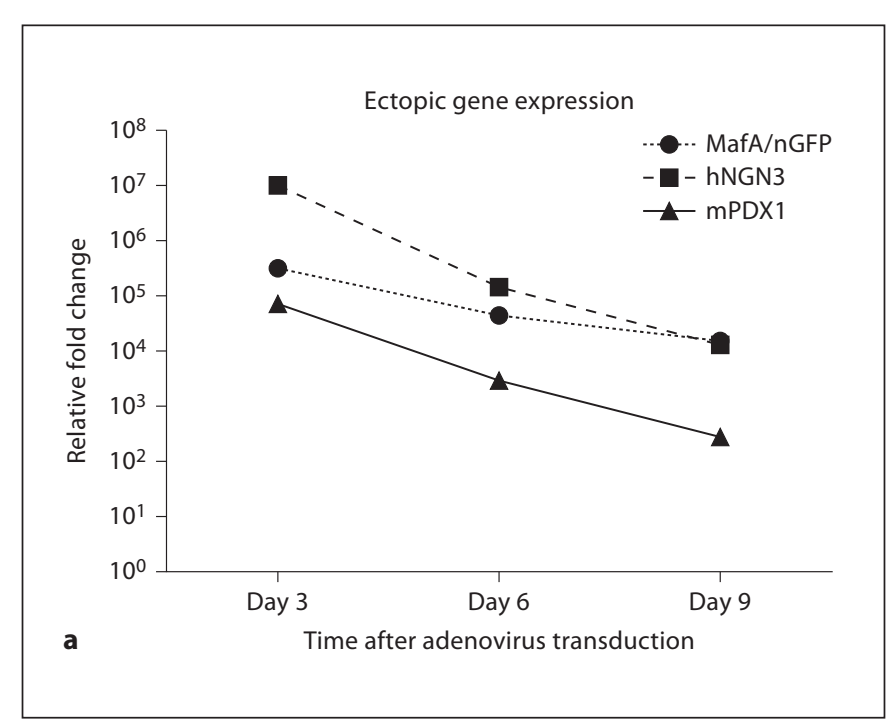

Fig. 3. Sustained endogenous expression of insulin, glucagon and NeuroD1 is dependent on transient overexpression of pancreatic transcription factors. a, b NHP7880 AFS cells were transduced with adenoviral vectors expressing Pdx1, Ngn3 and Mafa at 100 MOI each. Total RNA from transduced cells was extracted 3, 6 and 9 days after adenovirus infection. Ectopic (a) and endogenous (b) gene expression was measured using quantitative RT-PCR. c NHPAFS7880 were transduced with a combination of adenoviral vectors expressing Pdx1, Ngn3 and Mafa at 100 MOI each or with a 3-in-1 lentiviral vector expressing Pdx1, Ngn3 and Mafa. Total RNAs were extracted 6 days after virus transduction and quantitative RT-PCR was used to measure expression of Pdx1, Ngn3 and Mafa. Data was normalized to the expression in untransduced cells.

Further Induction of Pancreatic Gene Expression and Cell Survival by Media and Growth Substrate Modification

In all the experiments described above, nhpAFS cells were grown in Chang media [Chang et al., 1982] before and after adenoviral transduction to induce pancreatic transcription factor expression. The cells are able to proliferate in Chang media and remain in an undifferentiated state even after extensive passaging. It is possible that forcing transduced AFS cells to differentiate in media that otherwise was designed to maintain them in an undifferentiated state contributed to the observed toxicity. Recent publications showed the effect of different proteins and culture media components on the differentiation of stem cells towards endodermal and pancreatic lineages [Champeris Tsaniras, 2010; Chiou, 2011]. Five different 'induction' culture conditions were tested: Chang
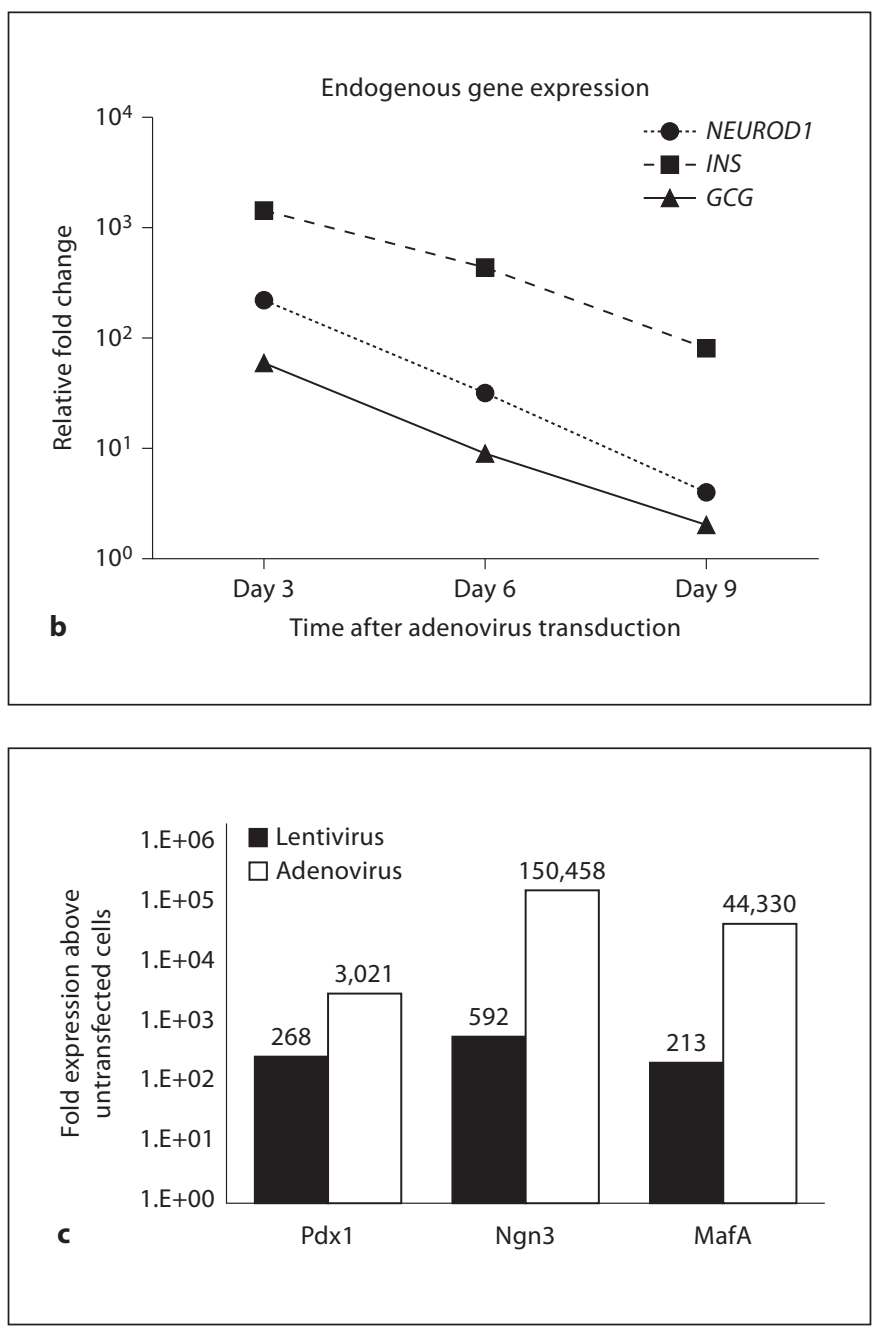

medium which contains 17\% ES-qualified FBS, $\alpha$-MEM with B27 supplement only; $\alpha$-MEM with B27 plus NAD; $\alpha$-MEM with B27 plus EGF (or betacellulin); $\alpha$-MEM with B27 plus NAD and EGF (or betacellulin). After transduction with all three transcription factors ( $\mathrm{PNM}=$ PDX1, NGN3 and MAFA) the cells were allowed to recover overnight in Chang media before being transferred to various induction media formulations for the 5-day period of differentiation. Figure 4a shows the average fold increase in insulin expression from two independent experiments on a representative nhpAFS cell line, NHP7231. Induction medium containing B27 increased insulin expression 5-fold over Chang media. An additional 2-fold increase was observed when NAD was added to the B27containing media. The pairwise combination of B27 plus EGF boosted insulin expression 17.7-fold over Chang media and when all three supplements were added together, 


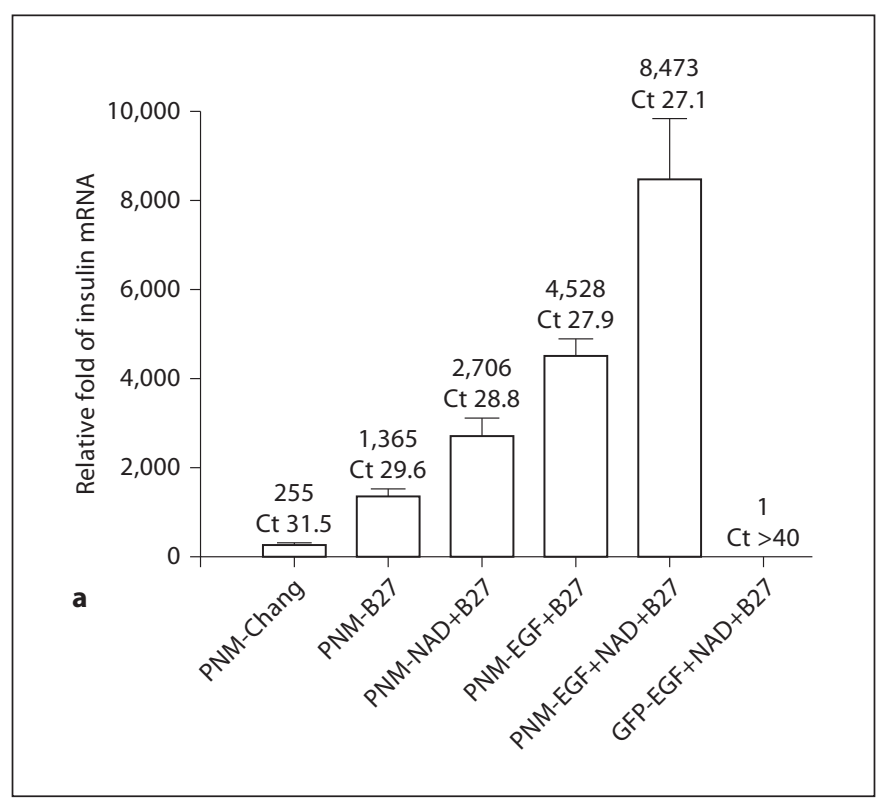

Fig. 4. Inclusion of growth factors and extracellular matrix coating improves cell survival and insulin expression in nhpAFS cell overexpression of pancreatic transcription factors. a NHPAFS 7231 were infected with a combination of adenoviral vectors expressing Pdx1, Ngn3 and Mafa. GFP-infected cells were used as controls. Cells were cultured in Chang media for $24 \mathrm{~h}$ and then the media was changed to include the different supplements and growth factors, as indicated. Quantitative RT-PCR analysis of the relative insulin expression levels was performed 5 days later. The

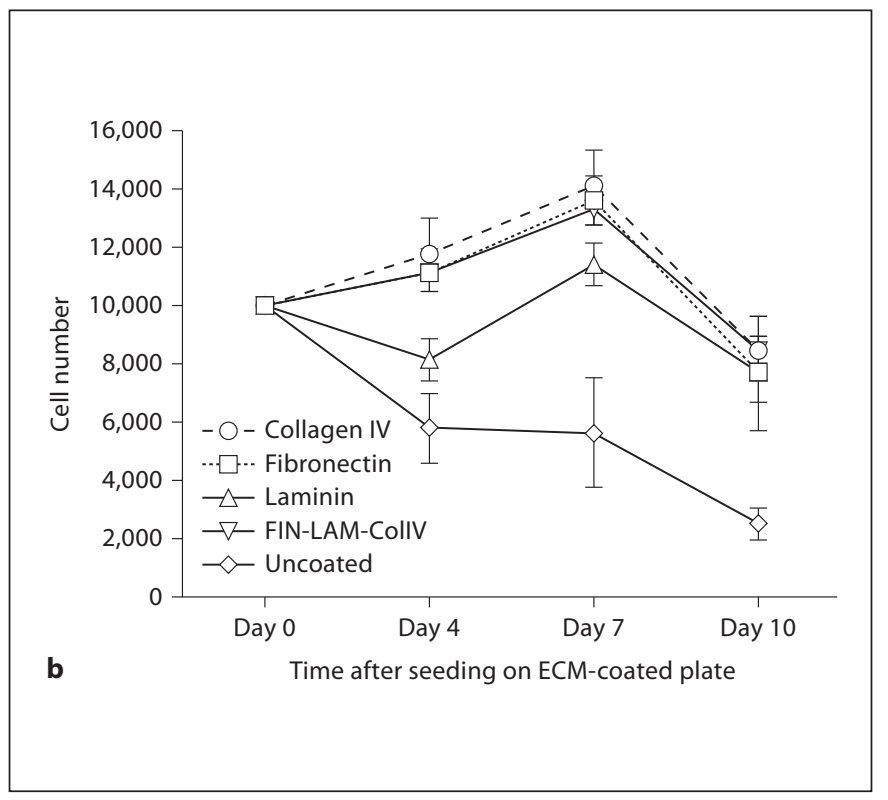

data represent the average relative fold compared with Ad-GFPinfected cells in 2 experiments. b NHP7880 AFS cells were infected with a combination of adenoviral vectors expressing Pdx1, Ngn3 and Mafa at 100 MOI each. Transduced cells were cultured in Chang's media for $72 \mathrm{~h}$ and collected by trypsinization. The cells were replated in a 96-well plate coated with different ECM protein at 10,000 cells per well (day 0). MTS assay was used to determine cell numbers after 4, 7 and 10 days, as indicated. The data represent the average cell number of 3 wells. insulin expression was increased a total of 33.2-fold over baseline. However, growth factor supplementation alone, without forced expression of pancreatic transcription factors, was insufficient to induce insulin expression on its own, as shown by the lack of insulin expression when nhpAFS cells were infected with a GFP-containing adenovirus and grown in $\alpha-\mathrm{MEM}+\mathrm{B} 27+\mathrm{NAD}+\mathrm{EGF}$.

ECM components have been shown to dramatically impact the viability of cultured $\beta$-cells and augment insulin secretion [Kaido et al., 2006; Gao et al., 2008]. To further support proliferation of nhpAFS cells, genetically modified to express pancreatic transcription factors, cells were seeded on various ECM-coated dishes. For these experiments, the nhpAFS cells were first transduced with all three transcription factors (PNM = PDX1, NGN3 and MAFA) and then plated in culture dishes coated with fibronectin, laminin or collagen IV, or a 1:1:1 combination of all three (fig. $4 \mathrm{~b}$ ). Laminin coating promoted better survival than uncoated plastic, but still showed a decrease in viability after initial plating like that seen with uncoated dishes. The extent of improved viability afforded by fibronectin and collagen IV were each individually better than laminin and both of them also eliminated the cell death that occurred between 0 and 4 days. The combination of all three ECM components was no different than fibronectin and collagen IV, each by itself, but these three groups enabled the nhpAFS cells to proliferate between plating and 7 days, which had not been seen before in previous experiments. However, between 7 and 10 days the viability of differentiating AFS cells under all ECM-containing growth conditions declined by approximately $40 \%$, and continued to decline thereafter. Therefore, the short-term viability of the cells was dramatically increased by plating on ECM components, but long-term survival was not improved.

\section{Discussion}

Amniotic fluid-derived stem cells, initially isolated as a c-kit-positive population from second trimester human amniocentesis samples, have been shown to differentiate 


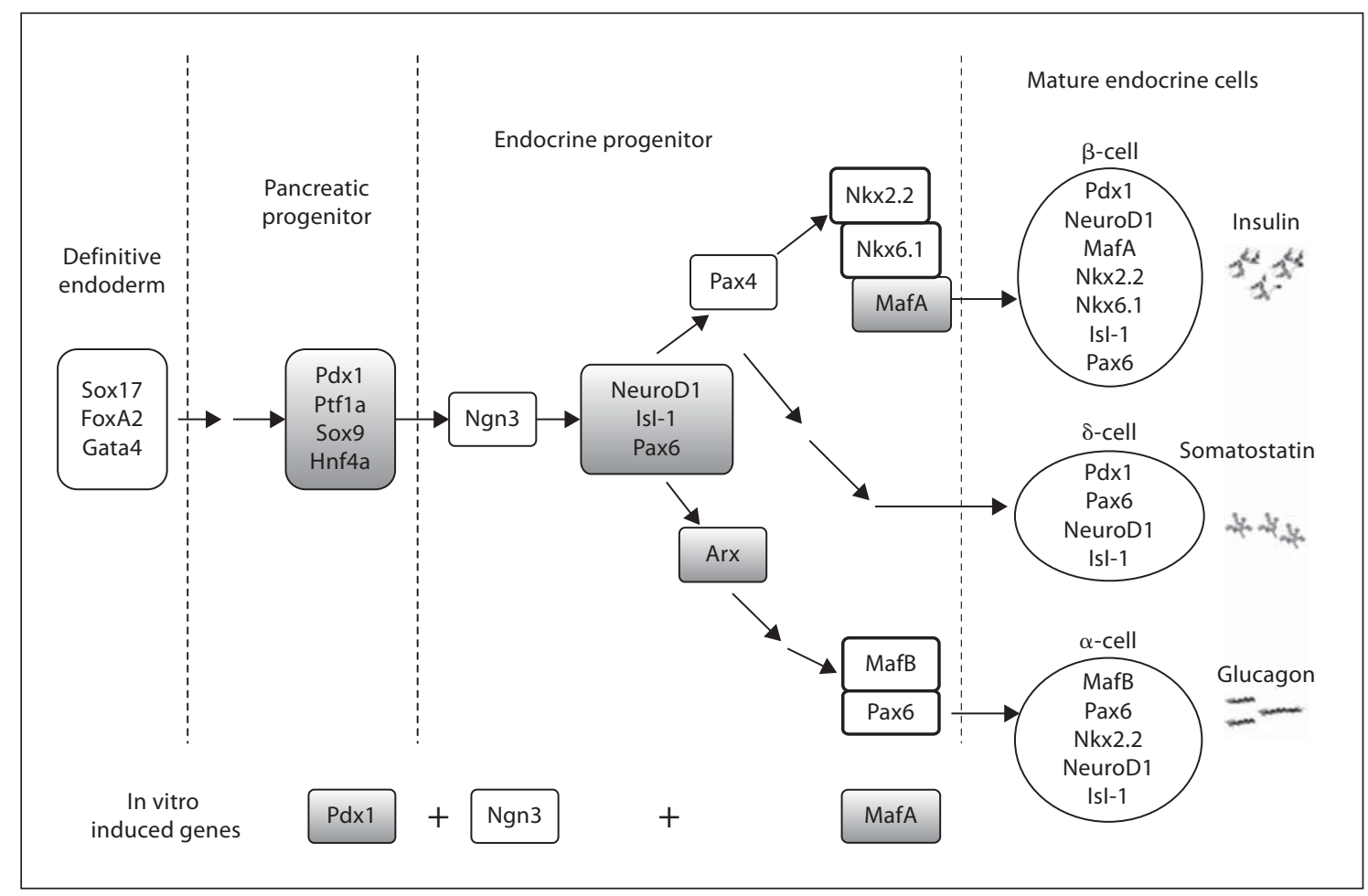

Fig. 5. Transcription factor hierarchy during pancreatic development. Among the various transcription factors involved in the pancreas formation and $\beta$-cell differentiation, Pdx1 plays a crucial role in pancreas and $\beta$-cell differentiation and maintenance of mature $\beta$-cell function. Ngn3 is an important factor for pancreatic endocrine cell differentiation and MafA expression is induced at the final stage of $\beta$-cell differentiation and functions as an activator of the insulin promoter. efficiently into mesenchymal lineages such as bone, cartilage, fat and muscle and, when cultured under specific inductive conditions, will express a subset of endodermal and ectodermal lineage markers. The fact that AFS cells do not form teratomas upon transplantation make them an attractive stem cell source for many cell therapies, regenerative medicine and tissue engineering applications. An equivalent AFS cell population has now been isolated from nhp with the intention of developing a clinically relevant model of diabetes for testing potential cellular therapies in our closest relatives. As a first step in that goal, this study expands the lineage repertoire of primate AFS cells and investigates whether these primitive cells can be induced to express genes associated with pancreatic endocrine differentiation by the introduction of three developmentally critical pancreatic transcription factors (fig. 5). This study goes on to show that if the partially differentiated AFS cells are exposed to growth conditions that more closely mimic the native $\beta$-cell microenvironment, enhanced pancreatic gene expression is observed. PDX1 alone induced glucagon expression in two of the
NHPAFS cell lines, NHP7880 and NHP7405, which interestingly express PAX6 and NKX6.1 in their undifferentiated state (table 1). Other groups have shown that PDX1 could induce high level glucagon expression in bone marrow MSCs and human pancreas-derived MSCs [Wilson et al., 2009], while a different group observed barely detectable levels of glucagon expression after PDX1 viral infection [Karnieli et al., 2007]. Similar to the data presented in table 1, both of these studies established that there is considerable donor variation in the expression of endogenous genes in MSCs, suggesting that PDX1-dependent differentiation toward the $\alpha$-cell lineage partially depends on what combination of genes are already present. Virally mediated NGN3 expression induced NeuroD1 expression in two out of the three cell lines. NeuroD1 is a key transcriptional regulator of pancreatic development and its promoter is a direct target of NGN3 [Huang et al., 2000]. In fact at least one publication introduces NeuroD1 directly, rather than depending on its activation downstream of NGN3 to induce pancreatic differentiation and insulin expression in a wide variety of 
cell types [Kaneto et al., 2009]. When MAFA was introduced by itself into AFS cells via viral transduction, lowlevel insulin expression was observed in two out of the three lines. MAFA is unique in being expressed exclusively in the final stages of $\beta$-cell differentiation and has been shown in various cell types to be a powerful inducer of insulin expression, but not important for $\beta$-cell development [Matsuoka et al., 2007]. In addition, glucosesensitive insulin expression is synergistically enhanced when MAFA is coexpressed, or expressed in sequence after PDX1 and either NGN3 or NeuroD1 [Andrali et al., 2008]. This observation is consistent with the results presented in table 2 and figure 2 showing that in all three AFS cell lines, insulin expression is increased 3- to 7-fold when PDX1, NGN3 and MAFA are coinfected and that this effect is not seen in primate skin fibroblasts. PDX1, MAFA and NeuroD1 can all directly bind to and activate the insulin promoter [Ohlsson et al., 1993; Naya et al., 1995; Olbrot et al., 2002; Zhang et al., 2009b] without reprogramming the cell. However, in our experiments concerted expression of other markers involved with development or maintenance of the pancreatic progenitor phenotype (Nkx2.2 and ISL1) as well as insulin processing (PCSK2), were also observed and cannot be explained by direct promoter binding. Therefore, we speculated that AFS cells did undergo a transient partial differentiation down the pancreatic lineage. The combinatorial nature of multiple transcription factors working in concert is consistent with the bulk of the literature on cellular reprogramming. Even though single transcription factors can target a specific promoter, synergistic induction is typically observed when multiple transcription factors are introduced, despite the fact that the second or third transcription factors do not bind directly to the promoter(s) of interest. For example, Gage et al. [2010] identified a combination of six adenovirally expressed transcription factors (PDX1, NGN3, MAFA, NEUROD1, ISL1 and PAX6) that could induce the human insulin promoter in amniotic fluid-derived cells. Interestingly, in their system, the combination of PDX1, NGN3 and MAFA could not induce insulin expression but the ISL1, PAX6 and MAFA triple combination could, although much less efficiently than all six. Four possibilities could explain the difference between the observations of Gage et al. [2010] and those of ours. First, the inducibility of undifferentiated cell lines might be linked to the combination of endogenously expressed transcription factors. The NHPAFS cell line (NHP7880) that showed the highest induction of all the pancreatic genes tested already expressed the highest endogenous level of PAX6. Second, it is possible that the species difference between human and primate may have a different genetic regulation and could affect the result. Third are the differences in the assay methods. Gage et al. [2010] used DsRed expression driven by human insulin promoter and found a six transcription factor combination was the best, whereas we used qRT-PCR method to detect endogenous insulin gene expression. The synthetic human insulin promoter may not completely mimic the activity of the endogenous promoter. The epigenetic stage could be very different in endogenous promoter compared to exogenous promoter [Wilson et al., 2009]. Finally, experimental conditions were different: Gage et al. [2010] used lower adenovirus titers (10 MOI of each viral construct) than we did (100 MOI), and low temperature $\left(30^{\circ}\right)$ for tissue culture to control cell proliferation. Although our studies are similar to others, any changes in the methods could have a significant difference in the outcomes, as seen in many other cases.

In an ongoing attempt to generate surrogate glucoseresponsive, insulin-secreting islet-like cells for the purpose of achieving a cell-based therapy for both T1D and late-stage type 2 diabetes, multiple in vitro approaches have been honed to increase efficiency and functional maturity [Tateishi et al., 2008; Borowiak et al., 2009; Chen et al., 2009; Zhang et al., 2009a; Champeris Tsaniras, 2010; Hui et al., 2010; Mayhew and Wells, 2010]. For obvious reasons, ES and iPS cells have been the most popular starting cell populations, but the likelihood of teratoma formation and need to 'finish' their differentiation in vivo has limited the excitement of this approach for clinical translation. Transdifferentiation of various somatic cell types, like hepatocytes and exocrine pancreatic cells, has both conceptual and pragmatic advantages. Both of these cell types are developmentally closer to islet endocrine tissue and therefore more likely to require less extensive input. In addition, the fact that they start out as terminally differentiated cells makes teratoma formation unlikely.

In addition to ES cells and various adult somatic cells, several non-c-kit-selected cell populations have also been isolated from human midgestation amniotic fluid, simply by virtue of their ability to adhere to tissue culture plastic, but the literature is unclear on whether any of them pass muster as bona fide stem cells. However, endocrine cell differentiation has yet to be conclusively demonstrated in any of the various amniotic fluid-derived cells. Two studies have cultured human amnion epithelial cells in NADcontaining media and were able to show that the resulting population was able to reverse hyperglycemia and weight loss in diabetic rodents [Wei et al., 2003; Hou et al., 2008]. 
However, those studies did not include sufficient characterization of the resulting $\beta$-cell-like population and failed to prove that the transplanted cells caused the diabetic reversal. Therefore, given the ease of obtaining fetal stem cells from amniotic fluid and their relative plentifulness after expansion, further investigation into their ability to differentiate into insulin-producing pancreatic progenitor cells is justified.

Although ectopic expression of transcription factors has been shown to be the principle driving force behind direct cellular reprogramming, it is clear that culture conditions also play an important role in facilitating and enhancing lineage-specific differentiation. Therefore, we postulated that the efficiency of $\beta$-cell differentiation would be improved if the culture conditions after viral transduction mimicked the native pancreatic microenvironment. Chang media was developed to provide optimal conditions for primary culture of human amniotic fluid cells and chorionic villus sample cultures for use in karyotyping and other antenatal genetic testing [Chang et al., 1982] but may not be ideal for $\beta$-cell differentiation. Here we found that including B27, a serum replacement widely used for $\beta$-cell differentiation, enhanced insulin expression approximately 5 -fold above that expressed in Chang media. Also, including NAD, a poly(adenosine diphosphate-ribose) synthetase inhibitor, led to a 2 -fold further enhancement of insulin expression, consistent with studies by Otonkoski et al. [1993] showing that NAD induced islet formation from pancreatic progenitor cells. Lastly, if betacellulin was added in combination with B27 and NAD, insulin expression increased a total of 30 -fold above that achieved in Chang media. Betacellulin, a member of the EGF growth factor family, was previously shown to sustain Pdx1 expression in isolated islets and to promote their maturation in vitro [Cho et al., 2008]. However, reagents used at early stages of ES cell differentiation toward the beta lineage, such as Activin A and retinoic acid, did not enhance insulin expression in our system (data not shown), suggesting that partially differentiated AFS cells can only respond to late-stage inductive signals.

Insulin mRNA was undetectable in AFS transduced with GFP adenovirus under the optimal differentiation media (fig. 4a). Thus, over-expression of the transcription factors was necessary to initiate cell differentiation. However, no c-peptide protein was detected in the PNM + $\mathrm{EGF}+\mathrm{NAD}+\mathrm{B} 27$-treated AFS cells and insulin mRNA was approximately 10,000 -fold less than that produced by isolated primate islets. Differentiation of AFS, using the $\beta$-cell differentiation protocols developed for ES cells or
MSCs without transcript factor overexpression failed to induce beta lineage marker expression.

AFS cells were originally cultured with Chang media, which contained a high concentration of serum (about $16 \%)$. In differentiation medium, 2\% B27 was used as a serum replacement. The low serum condition most likely caused the high rate of cell death, in both transcription factor overexpressed and control cells without transcription factor expression. We do not have evidence that the medium causes selective cell survival.

Increased AFS cell death and a decreased proliferation rate was observed after adenoviral transduction compared to untransduced controls. It has been demonstrated that ECM can support the in vitro long-term culture of pancreatic islets and protect pancreatic $\beta$-cells from apoptosis leading to improved cell survival [De Carlo et al., 2010]. It has also been reported that the peripheral ECM of mature human pancreas contains laminin, collagen IV and fibronectin [Stendahl et al., 2009]. Therefore, these three ECM proteins were included as plastic coatings in the differentiation system and were found to improve cell survival, while the benefit of augmenting insulin expression is inconclusive due to variation between the different primate AFS cell lines.

Figure 5 shows a schematic representation of the transcription factor cascade that ultimately leads to the $\alpha$-, $\beta$-, and $\delta$-cell pancreatic lineages and where the three transcription factors used in this study function in the cascade. PDX1 and NGN3 expression in primate AFS cells induced a gene expression profile indicative of the $\alpha$-cell lineage. However, when MAFA was expressed in combination with PDX1 and NGN3, the marker profile more closely resembled pancreatic progenitors early in the $\beta$-cell lineage. The schematic implies a sequential expression of these transcription factors during pancreatic differentiation; however, in our studies all three transcription factors were simultaneously coexpressed. Although transient, coordinated expression of endogenous endodermal, endocrine and pancreatic genes suggests that some level of cellular reprogramming was achieved in the primate AFS cells. However, the resulting, fairly robust expression of insulin was most likely a result of direct insulin promoter activation. In fact, sequential expression of PDX1, NGN3 and MAFA was less effective in inducing insulin expression than simultaneous coexpression of all three transcription factors. It is unknown whether transcription factor-induced AFS cells would continue to mature in a native pancreatic microenvironment, as has been demonstrated for partially differentiated ES cells [Kroon et al., 2008]. Therefore, a further 
characterization of the in vivo differentiation potential of partially reprogrammed AFS cells in a streptozotocin-induced mouse model of diabetes is warranted, given their promise as an easily obtained, highly expansive, relatively plastic and nontumorigenic candidate for a future cellular therapy for diabetes.

\section{Acknowledgements}

Part of this study was supported by a research grant 5R01EB8009 from NIBIB. The authors would like to acknowledge Dr. Mark Pettenati from Medical Genetics and the Wake Forest School of Medicine for his assistance in the karyotype analysis of the AFS cells.

\section{References}

Adeghate, E., P. Schattner, E. Dunn (2006) An update on the etiology and epidemiology of diabetes mellitus. Ann NY Acad Sci 1084: $1-29$.

-Andrali, S.S., M.L. Sampley, N.L. Vanderford, S. Ozcan (2008) Glucose regulation of insulin gene expression in pancreatic beta-cells. Biochem J 415: 1-10.

Ber, I., K. Shternhall, S. Perl, Z. Ohanuna, I. Goldberg, I. Barshack, L. Benvenisti-Zarum, I. Meivar-Levy, S. Ferber (2003) Functional, persistent, and extended liver to pancreas transdifferentiation. J Biol Chem 278: 31950 31957.

Berman, D.M., O. Cabrera, N.M. Kenyon, J. Miller, S.H. Tam, V.S. Khandekar, K.M. Picha, A.R. Soderman, R.E. Jordan, P.J. Bugelski, D. Horninger, M. Lark, J.E. Davis, R. Alejandro, P.O. Berggren, M. Zimmerman, J.J. O’Neil, C. Ricordi, N.S. Kenyon (2007) Interference with tissue factor prolongs intrahepatic islet allograft survival in a nonhuman primate marginal mass model. Transplantation 84: 308-315.

- Bigam, D.L., A.J. Shapiro (2004) Pancreatic transplantation: beta cell replacement. Curr Treat Options Gastroenterol 7: 329-341.

Borowiak, M., R. Maehr, S. Chen, A.E. Chen, W. Tang, J.L. Fox, S.L. Schreiber, D.A. Melton (2009) Small molecules efficiently direct endodermal differentiation of mouse and human embryonic stem cells. Cell Stem Cell 4: 348-358.

Bouwens, L., I. Rooman (2005) Regulation of pancreatic beta-cell mass. Physiol Rev 85: 1255-1270.

Cai, J., C. Yu, Y. Liu, S. Chen, Y. Guo, J. Yong, W. Lu, M. Ding, H. Deng (2010) Generation of homogeneous PDX1+ pancreatic progenitors from human ES cell-derived endoderm cells. J Mol Cell Biol 2: 50-60.

Carraro, G., L. Perin, S. Sedrakyan, S. Giuliani, C. Tiozzo, J. Lee, G. Turcatel, S.P. De Langhe, B. Driscoll, S. Bellusci, P. Minoo, A. Atala, R.E. De Filippo, D. Warburton (2008) Human amniotic fluid stem cells can integrate and differentiate into epithelial lung lineages. Stem Cells 26: 2902-2911.

Champeris Tsaniras, S, P.M. Jones (2010) Generating pancreatic beta-cells from embryonic stem cells by manipulating signaling pathways. J Endocrinol 206: 13-26.
Chang, H.C., O.W. Jones, H. Masui (1982) Human amniotic fluid cells grown in a hormone-supplemented medium: suitability for prenatal diagnosis. Proc Natl Acad Sci USA 79: 4795-4799.

Chen, S., M. Borowiak, J.L. Fox, R. Maehr, K. Osafune, L. Davidow, K. Lam, L.F. Peng, S.L. Schreiber, L.L. Rubin, D. Melton (2009) A small molecule that directs differentiation of human ESCs into the pancreatic lineage. Nat Chem Biol 5: 258-265.

Chiou, S.H., S.J. Chen, Y.L. Chang, Y.C. Chen, H.Y. Li, D.T. Chen, H.H. Wang, C.M. Chang, Y.J. Chen, H.H. Ku (2011) MafA promotes the reprogramming of placenta-derived multipotent stem cells into pancreatic isletslike and insulin ${ }^{+}$cells. J Cell Mol Med 15: 612-624.

Cho, Y.M., J.M. Lim, D.H. Yoo, J.H. Kim, S.S. Chung, S.G. Park, T.H. Kim, S.K. Oh, Y.M. Choi, S.Y. Moon, K.S. Park, H.K. Lee (2008) Betacellulin and nicotinamide sustain PDX1 expression and induce pancreatic beta-cell differentiation in human embryonic stem cells. Biochem Biophys Res Commun 366: 129-134.

D’Amour, K.A., A.G. Bang, S. Eliazer, O.G. Kelly, A.D. Agulnick, N.G. Smart, M.A. Moorman, E. Kroon, M.K. Carpenter, E.E. Baetge (2006) Production of pancreatic hormoneexpressing endocrine cells from human embryonic stem cells. Nat Biotechnol 24: 13921401.

Davis, S., M.D. Alonso (2004) Hypoglycemia as a barrier to glycemic control. J Diabetes Complications 18: 60-68.

De Carlo, E., S. Baiguera, M.T. Conconi, S. Vigolo, C. Grandi, S. Lora, C. Martini, P. Maffei, G. Tamagno, R. Vettor, N. Sicolo, P.P. Parnigotto (2010) Pancreatic acellular matrix supports islet survival and function in a synthetic tubular device: in vitro and in vivo studies. Int J Mol Med 25: 195-202.

De Coppi, P., G. Bartsch, M.M. Siddiqui, T. Xu, C.C. Santos, L. Perin, G. Mostoslavsky, A.C. Serre, E.Y. Snyder, J.J. Yoo, M.E. Furth, S. Soker, A. Atala (2007) Isolation of amniotic stem cell lines with potential for therapy. Nat Biotechnol 25: 100-106.
Fujikawa, T., S.H. Oh, L. Pi, H.M. Hatch, T. Shupe, B.E. Petersen (2005) Teratoma formation leads to failure of treatment for type I diabetes using embryonic stem cell-derived insulin-producing cells. Am J Pathol 166: 1781-1791.

Gage, B.K., M.J. Riedel, F. Karanu, A. Rezania, Y. Fujita, T.D. Webber, R.K. Baker, R.D. Wideman, T.J. Kieffer (2010) Cellular reprogramming of human amniotic fluid cells to express insulin. Differentiation 80: 130-139.

Gao, F., D.Q. Wu, Y.H. Hu, G.X. Jin (2008) Extracellular matrix gel is necessary for in vitro cultivation of insulin producing cells from human umbilical cord blood derived mesenchymal stem cells. Chin Med J (Engl) 121: 811-818.

Gomis, R., E. Esmatjes (2004) Asymptomatic hypoglycaemia: identification and impact. Diabetes Metab Res Rev 20(suppl 2): S47-S49.

Han, D., X. Xu, R.L. Pastori, C. Ricordi, N.S. Kenyon (2002) Elevation of cytotoxic lymphocyte gene expression is predictive of islet allograft rejection in nonhuman primates. Diabetes 51: 562-566.

Hering, B.J., R. Kandaswamy, J.D. Ansite, P.M. Eckman, M. Nakano, T. Sawada, I. Matsumoto, S.H. Ihm, H.J. Zhang, J. Parkey, D.W. Hunter, D.E. Sutherland (2005) Single-donor, marginal-dose islet transplantation in patients with type 1 diabetes. JAMA 293: 830-835.

-Hou, Y., Q. Huang, T. Liu, L. Guo (2008) Human amnion epithelial cells can be induced to differentiate into functional insulin-producing cells. Acta Biochim Biophys Sin (Shanghai) 40: $830-839$.

Huang, H.P., M. Liu, H.M. El-Hodiri, K. Chu, M. Jamrich, M.J. Tsai (2000) Regulation of the pancreatic islet-specific gene BETA2 (neuroD) by neurogenin 3. Mol Cell Biol 20: 3292-3307.

Hui, H., Y.G. Tang, L. Zhu, N. Khoury, Z. Hui, K.Y. Wang, R. Perfetti, V.L. Go (2010) Glucagon like peptide-1-directed human embryonic stem cells differentiation into insulinproducing cells via hedgehog, cAMP, and PI3K pathways. Pancreas 39: 315-322.

Ichii, H., C. Ricordi (2009) Current status of islet cell transplantation. J Hepatobiliary Pancreat Surg 16: 101-112. 
-Jiang, J., M. Au, K. Lu, A. Eshpeter, G. Korbutt, G. Fisk, A.S. Majumdar (2007a) Generation of insulin-producing islet-like clusters from human embryonic stem cells. Stem Cells 25: 1940-1953.

-Jiang, W., Y. Shi, D. Zhao, S. Chen, J. Yong, J. Zhang, T. Qing, X. Sun, P. Zhang, M. Ding, D. Li, H. Deng (2007b) In vitro derivation of functional insulin-producing cells from human embryonic stem cells. Cell Res 17: 333344.

Kaido, T., M. Yebra, V. Cirulli, C. Rhodes, G. Diaferia, A.M. Montgomery (2006) Impact of defined matrix interactions on insulin production by cultured human beta-cells: effect on insulin content, secretion, and gene transcription. Diabetes 55: 2723-2729.

-Kaneto, H., T.A. Matsuoka, N. Katakami, M. Matsuhisa (2009) Combination of MafA, PDX-1 and NeuroD is a useful tool to efficiently induce insulin-producing surrogate beta-cells. Curr Med Chem 16: 3144-3151.

Karnieli, O., Y. Izhar-Prato, S. Bulvik, S. Efrat (2007) Generation of insulin-producing cells from human bone marrow mesenchymal stem cells by genetic manipulation. Stem Cells 25: 2837-2844.

Kenyon, N.S., M. Chatzipetrou, M. Masetti, A. Ranuncoli, M. Oliveira, J.L. Wagner, A.D. Kirk, D.M. Harlan, L.C. Burkly, C. Ricordi (1999a) Long-term survival and function of intrahepatic islet allografts in rhesus monkeys treated with humanized anti-CD154. Proc Natl Acad Sci USA 96: 8132-8137.

-Kenyon, N.S., L.A. Fernandez, R. Lehmann, M. Masetti, A. Ranuncoli, M. Chatzipetrou, G. Iaria, D. Han, J.L. Wagner, P. Ruiz, M. Berho, L. Inverardi, R. Alejandro, D.H. Mintz, A.D. Kirk, D.M. Harlan, L.C. Burkly, C. Ricordi (1999b) Long-term survival and function of intrahepatic islet allografts in baboons treated with humanized anti-CD154. Diabetes 48: 1473-1481.

King, A.J., J.R. Fernandes, J. Hollister-Lock, C.E. Nienaber, S. Bonner-Weir, G.C. Weir (2007) Normal relationship of beta- and non-betacells not needed for successful islet transplantation. Diabetes 56: 2312-2318.

Kojima, H., M. Fujimiya, K. Matsumura, P. Younan, H. Imaeda, M. Maeda, L. Chan (2003) NeuroD-betacellulin gene therapy induces islet neogenesis in the liver and reverses diabetes in mice. Nat Med 9: 596-603.

Kroon, E., L.A. Martinson, K. Kadoya, A.G. Bang, O.G. Kelly, S. Eliazer, H. Young, M. Richardson, N.G. Smart, J. Cunningham, A.D. Agulnick, K.A. D’Amour, M.K. Carpenter, E.E. Baetge (2008) Pancreatic endoderm derived from human embryonic stem cells generates glucose-responsive insulinsecreting cells in vivo. Nat Biotechnol 26: 443-452.

Kutner, R.H., X.Y. Zhang, J. Reiser (2009) Production, concentration and titration of pseudotyped HIV-1-based lentiviral vectors. Nat Protoc 4: 495-505.
Leitao, C.B., P. Cure, T. Tharavanij, D.A. Baidal, R. Alejandro (2008) Current challenges in islet transplantation. Curr Diab Rep 8: 324331.

Luo, J., Z.L. Deng, X. Luo, N. Tang, W.X. Song, J. Chen, K.A. Sharff, H.H. Luu, R.C. Haydon, K.W. Kinzler, B. Vogelstein, T.C. He (2007) A protocol for rapid generation of recombinant adenoviruses using the AdEasy system. Nat Protoc 2: 1236-1247.

- Martin, G.R. (1981) Isolation of a pluripotent cell line from early mouse embryos cultured in medium conditioned by teratocarcinoma stem cells. Proc Natl Acad Sci USA 78: 76347638.

Matsuoka, T.A., H. Kaneto, R. Stein, T. Miyatsuka, D. Kawamori, E. Henderson, I. Kojima, M. Matsuhisa, M. Hori, Y. Yamasaki (2007) MafA regulates expression of genes important to islet beta-cell function. Mol Endocrinol 21: 2764-2774.

Mayhew, C.N., J.M. Wells (2010) Converting human pluripotent stem cells into beta-cells: recent advances and future challenges. Curr Opin Organ Transplant 15: 54-60.

Melendez-Ramirez, L.Y., R.J. Richards, W.T. Cefalu (2010) Complications of type 1 diabetes. Endocrinol Metab Clin North Am 39: 625640.

Mineo, D., A. Pileggi, R. Alejandro, C. Ricordi (2009) Point: steady progress and current challenges in clinical islet transplantation. Diabetes Care 32: 1563-1569.

Naya, F.J., C.M. Stellrecht, M.J. Tsai (1995) Tissue-specific regulation of the insulin gene by a novel basic helix-loop-helix transcription factor. Genes Dev 9: 1009-1019.

Ohlsson, H., K. Karlsson, T. Edlund (1993) IPF1, a homeodomain-containing transactivator of the insulin gene. EMBO J 12: 4251-4259.

Olbrot, M., J. Rud, L.G. Moss, A. Sharma (2002) Identification of beta-cell-specific insulin gene transcription factor RIPE3b1 as mammalian MafA. Proc Natl Acad Sci USA 99: 6737-6742.

Otonkoski, T., G.M. Beattie, M.I. Mally, C. Ricordi, A. Hayek (1993) Nicotinamide is a potent inducer of endocrine differentiation in cultured human fetal pancreatic cells. J Clin Invest 92: 1459-1466.

Perin, L., S. Sedrakyan, S. Giuliani, S. Da Sacco, G. Carraro, L. Shiri, K.V. Lemley, M. Rosol, S. Wu, A. Atala, D. Warburton, R.E. De Filippo (2010) Protective effect of human amniotic fluid stem cells in an immunodeficient mouse model of acute tubular necrosis. PLoS One 5: e9357.

Poggioli, R., R.N. Faradji, G. Ponte, A. Betancourt, S. Messinger, D.A. Baidal, T. Froud, C. Ricordi, R. Alejandro (2006) Quality of life after islet transplantation. Am J Transplant 6: 371-378.

Raikwar, S.P., N. Zavazava (2009) Insulin producing cells derived from embryonic stem cells: are we there yet? J Cell Physiol 218: 256263.
Ricordi, C., T.B. Strom (2004) Clinical islet transplantation: advances and immunological challenges. Nat Rev Immunol 4: 259-268.

Ryan, E.A., D. Bigam, A.M. Shapiro (2006) Current indications for pancreas or islet transplant. Diabetes Obes Metab 8: 1-7.

Ryan, E.A., B.W. Paty, P.A. Senior, D. Bigam, E. Alfadhli, N.M. Kneteman, J.R. Lakey, A.M Shapiro (2005) Five-year follow-up after clinical islet transplantation. Diabetes 54: 2060-2069.

Santiago, J.V. (1993) Lessons from the diabetes control and complications trial. Diabetes 42: 1549-1554.

$\checkmark$ Stendahl, J.C., D.B. Kaufman, S.I. Stupp (2009) Extracellular matrix in pancreatic islets: relevance to scaffold design and transplantation. Cell Transplant 18: 1-12.

Tao, B.T., D.G. Taylor (2010) Economics of type 1 diabetes. Endocrinol Metab Clin North Am 39: 499-512.

Tateishi, K., J. He, O. Taranova, G. Liang, A.C. D’Alessio, Y. Zhang (2008) Generation of insulin-secreting islet-like clusters from human skin fibroblasts. J Biol Chem 283: 31601-31607.

Thomson, J.A., J. Itskovitz-Eldor, S.S. Shapiro, M.A. Waknitz, J.J. Swiergiel, V.S. Marshall, J.M. Jones (1998) Embryonic stem cell lines derived from human blastocysts. Science 282: 1145-1147.

-Wagner, J.D., K. Kavanagh, G.M. Ward, B.J. Auerbach, H.J. Harwood Jr., J.R. Kaplan (2006) Old world nonhuman primate models of type 2 diabetes mellitus. Ilar J 47: 259-271.

Wei, J.P., T.S. Zhang, S. Kawa, T. Aizawa, M. Ota, T. Akaike, K. Kato, I. Konishi, T. Nikaido (2003) Human amnion-isolated cells normalize blood glucose in streptozotocin-induced diabetic mice. Cell Transplant 12: 545-552.

Wetekam, W., J. Groneberg, M. Leineweber, F. Wengenmayer, E.L. Winnacker (1982) The nucleotide sequence of cDNA coding for preproinsulin from the primate Macaca fascicularis. Gene 19: 179-183.

Wilson, L.M., S.H. Wong, N. Yu, E. Geras-Raaka, B.M. Raaka, M.C. Gershengorn (2009) Insulin but not glucagon gene is silenced in human pancreas-derived mesenchymal stem cells. Stem Cells 27: 2703-2711.

Zhang, D., W. Jiang, M. Liu, X. Sui, X. Yin, S. Chen, Y. Shi, H. Deng (2009a) Highly efficient differentiation of human ES cells and iPS cells into mature pancreatic insulin-producing cells. Cell Res 19: 429-438.

Zhang, H., W.P. Wang, T. Guo, J.C. Yang, P. Chen, K.T. Ma, Y.F. Guan, C.Y. Zhou (2009b) The LIM-homeodomain protein ISL1 activates insulin gene promoter directly through synergy with BETA2. J Mol Biol 392: 566577.

Zhou, Q., J. Brown, A. Kanarek, J. Rajagopal, D.A. Melton (2008) In vivo reprogramming of adult pancreatic exocrine cells to betacells. Nature 455: 627-632. 